Original Article

\title{
Comparison of antimicrobial resistance in Gram negative bacteria isolated from effluents in coastal districts of Karnataka, India
}

\author{
Juliet Roshini Mohan Raj ${ }^{1}$, Rajeshwari Vittal', Santosh Kogaluru Shivakumaraswamy³, Vijaya Kumar \\ Deekshit ${ }^{4}$, Indrani Karunasagar ${ }^{5}$ \\ 1,2,3,4,5 Division of Biomedical Sciences, Nitte Centre for Science Education and Research, Nitte Deemed to be University, \\ Derelakatte, M angalore-575018, India.
}

*Corresponding Author : Juliet Roshini Mohan Raj, Division of Biomedical Sciences, Nitte Centre for Science Education and Research, Paneer campus, Kotekar-Beeri Road, Derlakatte, M angalore - 575 018, India. E-mail : julietm@ nitte.edu.in

Received

: 18.04.2017

Review Completed : 30.04.2017

Accepted

02.05.2017

Keywords : effluents, drug resistance, determinants

\begin{tabular}{|c|}
\hline Access this article online \\
\hline Quick Response Code \\
\hline
\end{tabular}

\begin{abstract}
Downstream water systems provide for a conducive environment for horizontal gene transfer. The objective of this study was to determine the burden of antimicrobial resistance in waste water effluents from different sources and their impact on human health. Gram negative bacteria were isolated from 30 samples each of industrial, hospital and domestic effluents. The antimicrobial susceptibility of the 367 isolates from 90 effluent samples was determined by disc diffusion test and presence of antimicrobial resistance genes by polymerase chain reaction. Resistance to ampicillin was $62 \%$ in hospital effluents and was higher than that recorded for industrial and domestic effluents. While the highest percentage of resistance to tetracycline was observed in isolates from industrial effluents (42\%) a low of $9.5 \%$ was observed in hospital effluents. Antimicrobial resistance determinants present on mobile genetic elements were observed in a small fraction ( $10 \%)$ of the resistant isolates. The resistance profile of isolates in effluents reflect the practices of different industries. Resistant isolates in domestic effluents could be a reflection of the indiscriminate use of antibiotics andthat many of the contents of disinfectants and cleaning agents routinely used may contain structural analogs of antimicrobials used in therapy. Though by phenotypic test a higher prevalence of antimicrobial resistance was recorded the genotypic study revealed the prevalence to be low. This could be due to the limited number of antimicrobial resistance genes included in this study.
\end{abstract}

\section{Introduction}

Antibiotic resistance (AR) has escalated to one of the top health challenges that the world is presently facing. The overuse, inappropriate use and disposal of antibiotics for nonbacterial infections in communities and inadequate antibiotic stewardship in the healthcare facilities are among the prime reasons for the looming increase in the number and diversity of antimicrobial resistance observed ${ }^{1}$. Antibiotic use in agricultural practices and food animals is also a significant contributor to this global problem $^{2}$.

The presence of antibiotics, antimicrobial resistant bacteria(ARB) and antimicrobial resistance determinants(ARDs) in the same setting creates an environment that selects for $A R$ and provides an opportunity for genetic material housing ARDs to transfer between bacterial species via horizontal gene transfer ${ }^{3}$ Mobile genetic elements like plasmids, transposons, and bacterio phages promote horizontal gene transfer and facilitate the spread of antibiotic-resistance genes. Wastewater or effluents are the downstream sinks for all human practices and are therefore become reservoirs of bacteria and antibiotic resistance genes. These environments are hence pivotal in the dissemination of resistance genes.

Many studies that have attempted to study ARBs in wastewaters have been biased towards specific cultivable pathogenic or environmental species. The actual amount of resistance genes present in a given sample is hence underestimated. On the other hand, qualitative detection and quantitative methods by polymerase chain reaction $(P C R)$ used to investigate resistance genes in the microbial 
community in effluent waters do not give information on the species involved in harbouring and spreading the resistance genes ${ }^{4}$. Studies have linked the presence of ARBs in wastewaters to those of clinical importance and vice versa.

The objective of this study was to estimate the antimicrobial resistance burden of Gram negative bacteria in effluents which would give qualitative and quantitative information.

\section{Materials and Methods}

Samples: Grab samples of effluents from food processing industries, domestic and hospital effluents, were collected in sterile capped bottled at random time points (July 2014 to July 2016) from various locations in and around the coastal regions of Karnataka, India. The processing in the laboratory was generally within 4 hours of collection.

Bacterial isolates: Standard procedures for isolation of Vibrio spp, Pseudomonasspp. and Enterobacteriaceae members E. coli , Klebsiella spp., Enterobacter spp. and Salmonella spp., were followed ${ }^{5}$.For all the isolation dehydrated culture media ( HiMedia Laboratories ,India)was employed.

$5 \mathrm{ml}$ of the sample was inoculated into $45 \mathrm{~mL}$ of sterile lactose broth and $45 \mathrm{~mL}$ of sterile alkaline peptone water (APW) in flasks and incubated at $37^{\circ} \mathrm{C}$ and $30^{\circ} \mathrm{C}$ respectively for overnight enrichment. Serial tenfold dilutions of the enriched broth was prepared in physiological saline and $100 \mu \mathrm{L}$ of each dilutions was spread on the surface of selective solid agar. Inoculum from lactose broth was spread on MacConkey agar and from APW on thio sulphate citrate bile salts (TCBS) agar and incubated at $37^{\circ} \mathrm{C}$ and $30^{\circ} \mathrm{C}$ respectively for 18 to 24 hours. $1 \mathrm{ml}$ of the enrichment in lactose broth was inoculated into Selenite cysteine broth and tetrathionate $\mathrm{C} \mathrm{V}$ media for a second selective enrichment of Salmonella. Tubes were incubated at $37^{\circ} \mathrm{C}$ for 12 to 18 hours and then plated onto xylose lactose deoxycholate agar and bismuth sulphite agar respectively.

For isolation of Pseudomonas spp. samples were spread plated directly on cetrimide agar.
Typical colonies were picked in each case and purified on nutrient agar. Isolated colonies were subjected to a battery of biochemical test and this was complemented with PCR based methods for genotypic identification of $\mathrm{E}$. coli, Salmonella and Vibriospecies ${ }^{6.8}$. The reaction mixture consisted of $3 \mu$ l of $10 x$ buffer, $2.5 \mu \mathrm{M}$ each of the four deoxy nucleotide triphosphates (dNTPs), $1 \mu$ l of each primer and $0.3 \mu \mathrm{l}$ of Taq polymerase, $2 \mu \mathrm{l}$ of DNA template and volume made up to $30 \mu \mathrm{l}$ with nuclease free water. The PCR was performed in a programmable thermocycler (Applied biosystems, USA). Primers and annealing temperatures used are listed in table 1.The products were resolved by horizontal electrophoresis in a $1.5 \%$ agarose gel and analysed in a gel documentation system (Bio-Rad, USA).

Antimicrobial susceptibility test: Antimicrobial susceptibility test was carried out by disk diffusion method for antibiotics representing the major classes like penicillins (ampicillin $10 \mu \mathrm{g}$, piperacillin/ tazobactam $100 / 10 \mu \mathrm{g}$ ), cephalosporins (cefotaxime $30 \mu \mathrm{g}$ ), aminoglycosides (gentamicin $10 \mu \mathrm{g}$ ), quinolones (nalidixic acid 30 $\mathrm{g}$, ciprofloxacin $5 \mu \mathrm{g}$ ), chloramphenicol $30 \mu \mathrm{g}$, tetracycline $30 \mu \mathrm{g}$, nitrofurantoin $300 \mu \mathrm{g}$, sulphonamides (co-trimoxazole $25 \mu \mathrm{g}$ ) and carbapenems (imipenem 10 $\mu \mathrm{g}$, meropenem 10 $\mu \mathrm{g}$ ) as per Clinical Laboratory Standards International (CLSI) guidelines 2012. Commercial antimicrobial discs (HiM edia Laboratories, India were used for the test.

PCR based screening of antimicrobial resistance determinants (ARDs) was performed and products analysed as described earlier. Primers and annealing temperaturesused are listed in table 1.

Statistical analysis: One way ANOVA was applied to compare the quantification of antimicrobial resistant bacteria from different origin ${ }^{4}$ and $p<0.05$ was considered significant.

\section{Results}

367 Gram negative bacteria were isolated from 90 samples of which 125 were from industrial effluents, 116 from domestic effluents and 126 from hospital effluents.51 
isolates were identified as E. coli, 40 each as Vibrio and Citrobacter, 29 as Pseudomonas, 91 as Proteus, 15 as Klebsiella and 11 as Enterobacterbased on biochemical characterisation. In case of E. coli, Salmonella and Vibrio parahaemolyticus, the phenotypic identification was complemented by PCR based confirmation for uidA, invA and th genes respectively. 62 isolates were not identified up to the genus level as they did not show typical reactions of the major genera considered in this study. The distribution of identified genera is depicted in figure 1.

The antimicrobial susceptibility was tested by the disc diffusion method as per CLSI guidelines and the resistance pattern observed is depicted in figure 2 . Highest percentage of antimicrobial resistance was observed in hospital effluents with 78 of $126(62 \%)$ isolates being resistant to ampicillin, 53 and 34 of 125 isolates from industrial effluents showed resistance to tetracycline and nitro furantoin respectively. The resistance observed was at a higher frequency as compared to hospital effluent isolates
(12 of 126).It was significant to note that all isolates from industrial effluents were sensitive to ciprofloxacin while 48 (38\%) from hospital effluent were resistant to the same.

Presence of seventeen different ARD was tested by PCR. Though phenotypic resistance to any of the twelve antibiotics tested was observed in a minimum 4 isolates the number of resistant isolates carrying ARDs was low. The ARDs bla Стх-M $_{1}$, bla $_{\text {TЕM }}$ and tetD were observed in 2, 5 and 1 isolate from industrial effluents respectively.The ESBL encoding bla $\mathrm{T}_{\mathrm{TEM}}$ was detected in 11 isolates and bla $_{\text {СтT-M }}$ in 2 from domestic effluents. Sul genes that encode for sulphonamide resistance were present in 9 isolates from domestic effluents and in30 from hospital effluents. bla cTx. $_{\text {. }}$ ${ }_{м}$ and bla $_{\text {тем }}$ were observed in 14 isolates each from hospital effluents and NDM - 1 was observed in 4 isolates.

The number of resistant bacteria isolated from different effluents was significantly different as tested by ANOVA. The f-ratio value was 3.47752 and $p$-value 0.042614 .

Table 1 : Primers used in this study

\begin{tabular}{|c|c|c|c|c|}
\hline Target gene & Function & $\begin{array}{c}\text { Annealing } \\
\text { temperature }\end{array}$ & $\begin{array}{l}\text { Amplicon } \\
\text { size (bp) }\end{array}$ & Reference \\
\hline uidA & Beta glucoronidasespecific forE.coli & $63^{\circ} \mathrm{C}$ & 146 & 6 \\
\hline invA & Salmonella specific invasin & $64^{\circ} \mathrm{C}$ & 284 & 7 \\
\hline Tlh & V.parahaemolyticusthermolabile haemolysin & $63^{\circ} \mathrm{C}$ & 450 & 8 \\
\hline bla $_{\text {TEM }}$ & Beta lactamase & $63^{\circ} \mathrm{C}$ & 569 & 9 \\
\hline bla стx-M & Beta lactamase & $60^{\circ} \mathrm{C}$ & 356 & 9 \\
\hline tetA & Tetracyline resistance & $55^{\circ} \mathrm{C}$ & 494 & 10 \\
\hline tetB & Tetracyline resistance & $55^{\circ} \mathrm{C}$ & 571 & 10 \\
\hline tetC & Tetracyline resistance & $55^{\circ} \mathrm{C}$ & 418 & 10 \\
\hline tetD & Tetracyline resistance & $55^{\circ} \mathrm{C}$ & 546 & 10 \\
\hline tetE & Tetracyline resistance & $55^{\circ} \mathrm{C}$ & 544 & 10 \\
\hline tetG & Tetracyline resistance & $55^{\circ} \mathrm{C}$ & 550 & 10 \\
\hline sul I & Sulphonamide resistance & $55^{\circ} \mathrm{C}$ & 425 & 10 \\
\hline sul II & Sulphonamide resistance & $55^{\circ} \mathrm{C}$ & 435 & 10 \\
\hline sul III & Sulphonamide resistance & $55^{\circ} \mathrm{C}$ & 792 & 10 \\
\hline qnrA & Quinolone resistance & $53^{\circ} \mathrm{C}$ & 516 & 11 \\
\hline qnrB & Quinolone resistance & $53^{\circ} \mathrm{C}$ & 469 & 11 \\
\hline qnrs & Quinolone resistance & $53^{\circ} \mathrm{C}$ & 417 & 11 \\
\hline qepA & Quinolone resistance & $60^{\circ} \mathrm{C}$ & 403 & 12 \\
\hline NDM -1 & Beta lactamase & $60^{\circ} \mathrm{C}$ & 621 & 13 \\
\hline $\operatorname{aac}\left(6^{\prime}\right)-\mathrm{Ib}-\mathrm{cr}$ & Multi drug resistance & $57^{\circ} \mathrm{C}$ & 482 & 14 \\
\hline
\end{tabular}




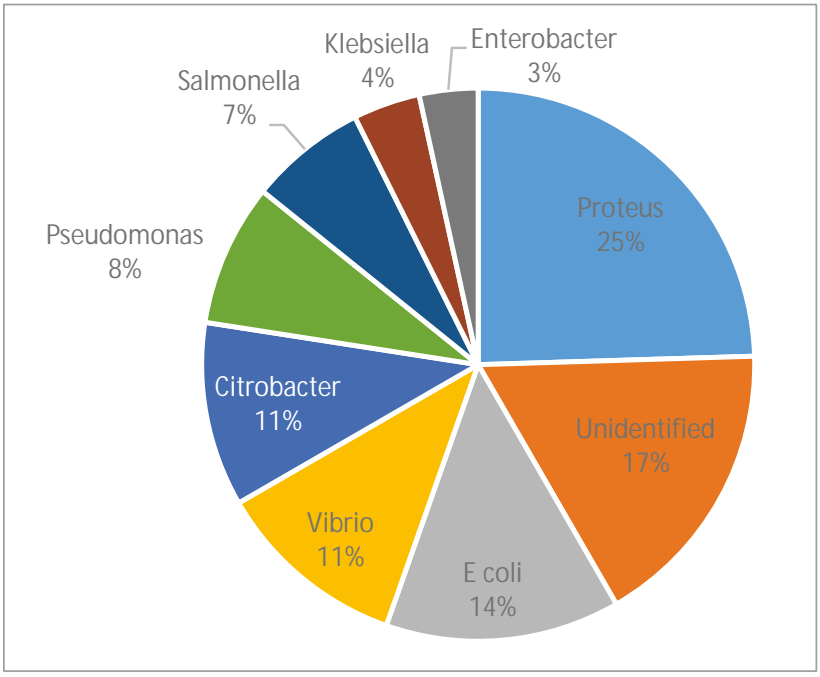

Figure 1 : Gram negative bacteria isolated from effluents

\section{Discussion}

Wastewater can be a potential source of pathogenic resistance determinant carrying bacteria. Traces of antibiotics in urine, faeces, as well as improperly discarded antibiotics get channelled into effluents especially in the domestic and hospital sector. Wastewater treatment does not ensure complete biodegradation of all antibiotics and hence these downstream environments provide for a suitable means of accumulation and dissemination of antimicrobial resistance ${ }^{15-17}$.

Studies comparing antibiotic resistant bacteria and their resistance genes in municipal and hospital wastewaters have reported that municipal wastes and hospital effluents as carriers of identical load of $\mathrm{ARBs}^{18}$. In this study however, a significant difference $(p \varangle 0.05)$ in the number of ARB from different effluents was observed. While we have isolated bacteria and then screened for antimicrobial resistance the mentioned study had determined counts on antibiotic containing medium which may be the reason for differences observed.

The resistance profile of isolates in effluents reflect the practices of different industries. A high degree of resistance to most of the antibiotic tested was observed in hospital effluents. Nalidixic acid, ciprofloxacin, ampicillin and cefotaxime are frequently used in infection treatment and hence the resistance to these antibiotics in hospital effluent was far greater than those observed in other

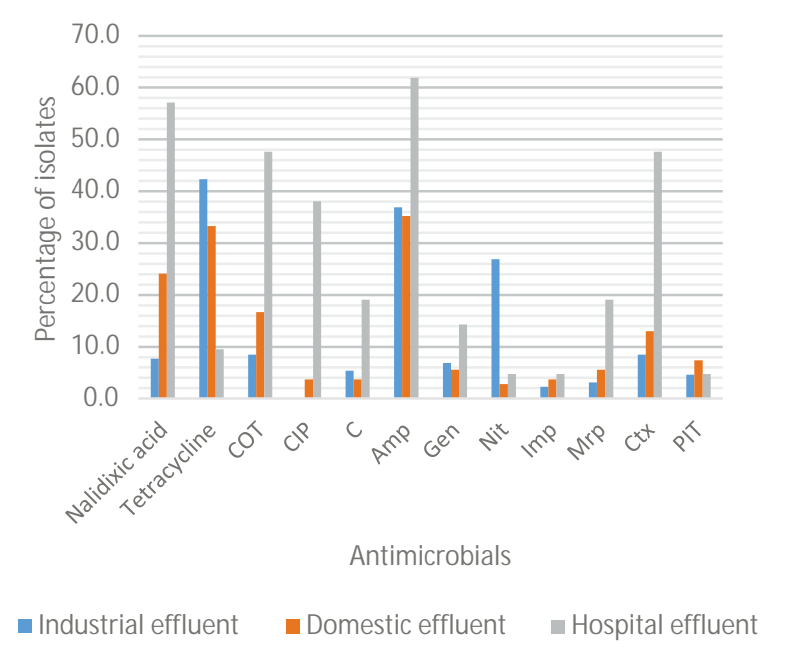

Figure 2 : AMR isolates in different effluents

effluents tested. The frequency of resistance to tetracycline and nitrofurantoin in industrial effluents was the highest of all effluent types which may be a reflection of the practices in the related production sources. The fluoroquinolones, $\beta$-lactams, sulphonamides, and tetracyclines are reported to be used in animal husbandry as growth promoters ${ }^{19}$. Tetracyclines are among the most frequently and extensively used antibiotics in livestock and poultry worldwide ${ }^{20}$. The wide-spread use of nitrofurans in poultry industry has been reported and it has been suggested that the positive pressure by this antimicrobial might also be involved in the selection and persistence of Salmonella in animals used for food production ${ }^{21}$.

A high incidence of resistant isolates in domestic effluents in this study reflects purchase and use of antibiotics across the counter. Further, many disinfectants and cleaning agents routinely used have in them compounds which may act as structural analogs of antimicrobials used in therapy ${ }^{22}$. The low incidence of the resistance determinants could be due to the limited number of ARDs tested as against the diversity of genes and factors that are responsible for antimicrobial resistance.

\section{Conclusion}

Studies on antimicrobial resistance in effluents have generally looked into the quantification of resistance determinants or diversity of bacteria in effluents. We have 
expanded the perspective of such studies in looking into many bacterial genera and resistance determinants in effluents simultaneously. The data thus generated can be used to suggest the implementation of antimicrobial usage in all sectors such as domestic, industrial and hospital front.

\section{References}

1. World Health Organization. WHO global strategy for containment of antimicrobial resistance. 2001.

2. Landers TF, Cohen B, Wittum TE, Larson EL. A review of antibiotic use in food animals: perspective, policy, and potential. Public health reports. 2012 Jan;127(1):4-22.

3. Moura A, Henriques I, Smalla K, Correia A. Wastewater bacterial communities bring together broad-host range plasmids, integrons and a wide diversity of uncharacterized gene cassettes. Research in microbiology. 2010 Feb 28;161(1):58-66

4. Laht M, Karkman A, Voolaid V, Ritz C, Tenson T, Virta M, Kisand V. Abundances of tetracycline, sulphonamide and beta-lactam antibiotic resistance genes in conventional wastewater treatment plants (WWTPs) with different waste load. PloS one. 2014 Aug 1;9(8):e103705..

5. Food and Drug Administration. Bacteriological analytical manual. Revision A.

6. Bej AK, Dicesare JL, Haff L, Atlas RM . Detection of Escherichia coli and Shigella spp. in water by using the polymerase chain reaction and gene probes for uid. Applied and Environmental Microbiology. 1991 Apr 1;57(4):1013-7.

7. Rahn K,De Grandis SA,Clarke RC , et al.Amplification of an invA gene sequence of Salmonella typhimurium by polymerase chain reaction as a specific method of detection of Salmonella.Molecular Cell Probes,1992; 6(4):271-279.

8. Taniguchi HA, Ohta HI, Ogawa MI, Mizuguchi YA. Cloning and expression in Escherichia coli of Vibrio parahaemolyticus thermostable direct hemolysin and thermolabile hemolysin genes. Journal of bacteriology. $1985 \mathrm{M}$ ay 1;162(2):510-5.

9. Colomer-Lluch M, Jofre J, M uniesa M. Antibiotic resistance genes in the bacteriophage DNA fraction of environmental samples. PloS one. $2011 \mathrm{Mar}$ 3;6(3):e17549.

10. M a Y, Wilson CA, Novak JT, Riffat R, Aynur S, M urthy S, Pruden A. Effect of various sludge digestion conditions on sulfonamide, macrolide, and tetracycline resistance genes and class I integrons. Environmental science \& technology. 2011 Aug 19;45(18):7855-61.

11. Robicsek A, Strahilevitz J, Sahm DF, Jacoby GA, Hooper DC. qnr prevalence in ceftazidime-resistant Enterobacteriaceae isolates from the United States. Antimicrobial agents and chemotherapy. 2006 Aug 1;50(8):2872-4

12. Chen X, Zhang W, Pan W, Yin J, Pan Z, Gao S, Jiao X. Prevalence of qnr,

\section{Acknowledgement}

The authors are grateful to Indian Council for Medical Research for providing financial support through the research grant AMR/37/2011-ECD-1. We thank Nitte (Deemed to be University) for providing the required infrastructure.

aac (6') $-\mathrm{lb}$-cr, qepA, and oqxAB in Escherichia coli Isolates from Humans, Animals, and Environment. Antimicrobial agents and chemotherapy. $2012 \mathrm{M}$ ar 5:AAC-06191

13. Nordmann P, Poirel L, Carrër A, Toleman MA, Walsh TR. How to detect NDM-1 producers. Journal of clinical microbiology. 2011 Feb 1;49(2):718-21

14. Park CH, Robicsek A, Jacoby GA, Sahm D, Hooper DC. Prevalence in the United States of aac (6') -lb-cr encoding a ciprofloxacin-modifying enzyme. Antimicrobial agents and chemotherapy. 2006 Nov 1:50(11):3953-5.

15. Aali R, Nikaeen M, Khanahmad H, Hassanzadeh A. Monitoring and Comparison of Antibiotic Resistant Bacteria and Their Resistance Genes in M unicipal and Hospital Wastewaters. International J ournal of Preventive M edicine. 2014:5(7):887-894.

16. Gao L.,Shi Y, Li W, Niu H, Liu J, Cai Y. Occurrence of antibiotics in eight sewage treatment plants in Beijing, China. Chemosphere 2010, 86, 665-671. 53.

17. Gibs J, Heckathorn HA, M eyer MT, Klapinski FR, Alebus M, Lippincott RL. Occurrence and partitioning of antibiotic compounds found in the water column and bottom sediments from a stream receiving two wastewater treatment plant effluents in Northern New Jersey, 2008. Science of the Total Environment. 2013 Aug 1;458:107-16.

18. Alam MZ, Aqil F, Ahmad I, Ahmad S. Incidence and transferability of antibiotic resistance in the enteric bacteria isolated from hospital wastewater. Brazilian Journal of Microbiology. 2013 Sep;44(3):799 806.

19. Hughes P, Heritage J. Antibiotic growth-promoters in food animals. FAO Animal Production and Health Paper. 2004:129-52.

20.Granados-Chinchilla F, Rodríguez C. Tetracyclines in Food and Feedingstuffs: From Regulation to Analytical Methods, Bacterial Resistance, and Environmental and Health Implications. Journal of Analytical Methods in Chemistry. 2017Jan 12;2017.

21. Antunes P, Machado J, Peixe L. Illegal use of nitrofurans in food animals: contribution to human salmonellosis? Clinical microbiology and infection. 2006 Nov 1;12(11):1047-9

Aiello AE, M arshall B, Levy SB, Della-Latta P, Larson E. Relationship between triclosan and susceptibilities of bacteria isolated from hands in the community. Antimicrobial agents and chemotherapy. 2004 Aug 1;48(8):2973-9. 